\title{
Sleep abnormalities in schizophrenia: pathophysiological
} significance ${ }^{1}$

The notion that sleep, dreams and psychosis are interrelated dates back to Hughlings Jackson, who, over a century ago, said, 'Find out about dreams, and you will find about insanity' (Jackson, 1958). The discovery in 1953 of the rapid eye movement (REM) sleep and its association with dreaming led to a surge of interest in the association between sleep and psychoses. Several sleep electroencephalographic (EEG) abnormalities have since been reported in schizophrenia; these include reduced total sleep, impaired sleep continuity, shortened (REM) latency, and reduced slow wave sleep (SWS, or delta EEG activity) (Keshavan et al. 1990a). Eleven of the 14 studies that compared REM latency between drug-free schizophrenics and normal controls (Gulevich et al. 1967; Stern et al. 1969; Dürrigl et al. 1973; Jus et al. 1973; Benson \& Zarcone, 1985, 1993; Hiatt et al. 1985; Zarcone et al. 1987; Kempenaers et al. 1988; Keshavan et al. 1990b; Tandon et al. 1992) showed a reduction in REM latency in schizophrenic patients, though some studies (Feinberg $e t$ al. 1964; Caldwell \& Domino, 1967; Ganguli et al. 1987) have not found such a reduction. In addition, a large meta-analytical study of controlled studies (Benca et al. 1992) confirmed this finding. Seven of 10 studies (Lairy et al. 1965; Caldwell \& Domino, 1967; Jus et al. 1968; Kupfer et al. 1970; Traub, 1972; Hiatt et al. 1985; Benson \& Zarcone, 1993) have shown a reduction of hand-scored SWS in schizophrenic patients, though there have been some negative studies (Ganguli et al. 1987; Kempenaers et al. 1988; Tandon et al. 1992). However, Ganguli et al. (1987) observed a significant reduction in delta wave counts in drug-naive schizophrenic patients, suggesting that hand-scored SWS may not be sensitive enough and automated counts may be a better marker of SWS deficiency in schizophrenia.

The implications of these findings for the diagnosis and pathophysiology of schizophrenia remain unclear. Disrupted sleep continuity, shortening of REM latency; and reduced SWS are also seen in affective disorders (Reynolds \& Kupfer, 1987; Benca et al. 1992); the similarity between affective and schizophrenic disorders suggests that these findings may lack diagnostic specificity. There may, however, be some differences. While an increase in REM sleep in affective disorder is supported by findings of significant increases in REM density, time and percentage in controlled studies, no consistent changes have been seen in the amounts of REM sleep in schizophrenia (Benca et al. 1992). Thus, a combination of EEG sleep abnormalities (decreased REM latency and SWS deficits without appreciable alterations in REM sleep amounts) might be seen in schizophrenia. A clarification of the biological basis for such a constellation of findings could be instructive toward our understanding of the pathophysiology of schizophrenic disorders.

\section{REM SLEEP}

There may be several explanations for the observed shortening of REM sleep latencies in schizophrenic and affective disorders. First, it is conceivable that REM latency alterations in schizophrenia are related to the presence of depressive symptoms in schizophrenic patients. No such relationship between REM latency and affective symptomatology has been observed in schizophrenic patients, however (Tandon et al. 1992). There is a genetic overlap between these

\footnotetext{
* Address for correspondence: Dr Matcheri S. Keshavan, Departnınt of Psychiatry, Western Psychiatric Institute and Clinic, 3811 O'Hara Street, Pittsburgh, PS 15213, USA.
} 
disorders, with many schizophrenic patients having family members with affective disorders and vice versa (Gershon et al. 1988). It is therefore possible that some schizophrenic patients may be biologically similar to affective disorder; such patients may be expected to have sleep findings similar to those in affective disorders. Preliminary data on this issue are contradictory (Keshavan et al. $1990 \mathrm{~b}$; Tandon et al. 1992). This hypothesis, therefore, needs further rigorous testing.

Secondly, there may be common neurochemical mechanisms mediating the sleep findings in schizophrenia and affective disorders. Cholinergic mechanisms, which have been postulated to underlie shortened REM latency sleep in affective disorders (Sitaram et al. 1980) may be involved in schizophrenia as well (Tandon \& Greden, 1989). At least seven studies have shown to date that patients with affective disorder have a rapid (supersensitive) induction of REM sleep with cholinergic agonists (Gillin et al. 1991). Schizophrenic patients have been described to show a similar rapid (supersensitive) REM sleep induction with the oral muscarinic cholinergic agonist RS86 (Riemann et al. 1991) and a reduced prolongation of REM latency with the muscarinic antagonist biperiden (Tandon et al. 1991). There is also preliminary evidence for increased plasma cholinesterase (ChE) activity (Mahadik et al. 1989) and an inverse relation between plasma ChE and REM latency in schizophrenic patients (Keshavan et al. 1992). Increased cholinergic activity may thus be one possible explanation for the shortened REM sleep latency in affective and schizophrenic disorders. On the other hand, dopaminergic and noradrenergic (van Kammen et al. 1990) systems which are presumably hyperactive during acute episodes of schizophrenia, are inhibitory to REM sleep, while cholinergic mechanisms enhance REM sleep. The timing of onset of REM sleep is, however, mainly cholinergically mediated (Gillin et al. 1978). Thus, while cholinergic hyperactivity would explain the shortened REM latency, the concomitant NE/DA overactivity would counter the cholinergically-mediated REM sleep increases (explaining the absence of increased REM sleep in schizophrenia).

Thirdly, it is also possible that REM latency reductions in schizophrenia results from a deficit in SWS (Borbély, 1982; Feinberg et al. 1988). The latter possibility is supported by observations of an inverse relation between daytime naps (which lead to reduced night-time SWS) and REM latency (Campbell \& Gillin, 1987). Kupfer \& Ehlers (1989) have proposed that two distinct factors ('roads') may lead to shortening of REM latency in affective illness: type 1, a 'trait' marker, due to SWS deficiency, perhaps related to genetic vulnerability to affective illness and developmental factors, and type 2, an 'episode' marker, due to REM pressure, perhaps related to stress and illness severity. The lack of consistent changes in REM sleep amounts and the findings of reduced SWS in schizophrenia suggests that a mechanism similar to the Road I to REM latency might operate in schizophrenia. In this sense, the SWS deficits may be the primary sleep abnormality in schizophrenia.

\section{SLOW-WAVE SLEEP}

What is the pathophysiological significance of SWS deficits in schizophrenia? Some clues to this may derive from the studies of the ontogeny of sleep during normal adolescence, and in the context of a neurodevelopmental framework for schizophrenia (Feinberg, 1982; Waddington, 1993). One of the essential characteristics of schizophrenia is its onset in adolescence. Human adolescence is associated with a substantial reorganization of the brain structure and function, resulting in an initial increase and a subsequent decrease of cortical synaptic density proceeding through adolescence (Huttenlocher, 1979). This is paralleled by reductions in synaptic density, brain cortical volume, regional brain metabolism and deep sleep during the second decade of life (Feinberg, 1982, 1990). It has been proposed that such a process of programmed synaptic elimination, or 'pruning', may be exaggerated in schizophrenia (Feinberg, 1982; Hoffman \& McGlashan, 1993). If this is true, first, one would expect deficits in these parameters in schizophrenia; observations of decreased grey matter volume, in magnetic resonance imaging (MRI) studies (Zipursky et al. 1992), possibly increased neuronal density, which may be related to loss of neuropil comprising of synapses (Selemon et al. 1993), and of decreased SWS in schizophrenia, as reviewed above, are consistent with this possibility. Secondly, one would expect an association between SWS deficits and indicators 
of cerebral dysfunction in schizophrenia. Indeed, SWS deficits have been found to be associated with negative symptoms (Ganguli et al. 1987), cognitive impairment (Orzack et al. 1977), and with cerebral ventricular enlargement (van Kammen et al. 1988). Negative symptoms, cognitive impairments and ventriculomegaly are considered to reflect trait related alterations, which appear to be present at and may even precede illness onset, thus supporting the notion of neurodevelopmental abnormalities of schizophrenia (Mukherjee et al. 1991; also see Waddington, 1993 for a review). Decreased SWS in schizophrenia may therefore be related to alterations in brain structure and function perhaps related to such a neurodevelopmental abnormality.

How does one understand deficits in SWS in the context of the possibly reduced cortical synaptic density in schizophrenia? EEG waves are thought to reflect summed post-synaptic potentials in large assemblies of cortical neurons driven by a subcortical 'pacemaker' (Elul, 1972). Decreased synaptic density, therefore, could result in smaller EEG waves (and thus resulting in reduced SWS) by decreased membrane surface (fewer dendrites/neuron) causing a smaller voltage response to the synchronizing stimulus (Feinberg et al. 1990). Further, lower levels of interconnection would cause smaller aggregations of neurons to simultaneously change potential. Miles \& Dement (1980) have suggested that the age-related reduction in delta sleep may be related to loss of oblique-horizontal dendrite system of layers 2, 3, and 5. Pyramidal cells, which may be involved in synchronous neuronal behaviour mediating delta sleep. Perhaps such an age-related neuronal decrement is exaggerated in schizophrenia.

Do SWS deficits reflect widespread brain dysfunction, or is there a regional specificity? Kraepelin (1919) originally proposed that schizophrenia 'attacks by preference the prefrontal cortex'. Interest in the role of the prefrontal cortex (PFC) in pathophysiology of schizophrenia has been rekindled by observations of consistently reduced metabolism in this region ('hypofrontality') from a variety of approaches, including positron emission tomography (PET) studies (Buchsbaum, 1993), single photon emission tomography (SPECT) studies (Andreasen et al. 1992), magnetic resonance spectroscopy (MRS) studies (Pettegrew et al. 1991), and electrophysiological studies of cortical coherence (Hoffman et al. 1991). The PFC is the site of most intense cortical brain activity during the awake state in normal humans, and the reverse is true during SWS. The delta EEG activity is most prominent in the PFC (Horne, 1992, 1993). Further, data from coherence analysis of EEG support the view that the PFC may play a role in the generation of SWS (Nielsen et al. 1991). The cognitive effects of sleep deprivation in normal subjects appear to resemble closely PFC dysfunction (Horne, 1993). These data, albeit circumstantial, suggest an association between hypofrontality and deficits in SWS, even though the direction of causation remains unclear.

\section{DISCUSSION}

Schizophrenia appears to be marked by a polysomnographic profile of shortened REM latency without alterations in REM sleep amounts and reduced amounts of slow-wave sleep. While similarity in these findings between schizophrenia and affective disorder reflects a lack of diagnostic specificity, these similarities perhaps suggest common neurobiological mechanisms. The changes in REM latency in these disorders might reflect similar alterations in cholinergic function. An intriguing alternative possibility is that the sleep EEG alterations reflect a neurodevelopmental abnormality, perhaps an excessive cortical synaptic pruning during adolescence, perhaps more so in the PFC. However, these possibilities must at this time be considered speculative. Future studies need to examine EEG sleep findings in schizophrenia, paying close attention to the state vs. trait differences and the question of whether these findings are present at illness onset. The neurochemical correlates of sleep changes and the effects of pharmacological challenges (dopaminergic, cholinergic, etc.) are a worthwhile aspect of enquiry. The neurodevelopmental aspects of sleep EEG, examining the maturational changes in sleep during adolescence in healthy and schizophrenic subjects need to be studied. Finally, the association between sleep changes and neuroanatomical and physiological alterations need to be examined using state-of-the-art imaging approaches such as MRI, MRS, and 
PET studies. Such studies may help us to more fully exploit the use of sleep EEG as a window to the brain capable of providing clues to the pathophysiology of puzzling disorders such as schizophrenia.

\author{
M. S. KESHAVAN AND R. TANDON
}

The preparation of this editorial was supported by an NIMH grant (MH-45203) to M.S.K. We wish to thank Dr David J. Kupfer for his valuable suggestions.

\section{REFERENCES}

Andreasen, N. C., Rezai, K., Alliger, R., Swayze II, V. W., Falum, M., Kirchner, P., Cohen, G. \& O'Leary, D. S. (1992). Hypofrontality in neuroleptic-naive patients and in patients with chronic schizophrenia. Archives of General Psychiatry 49, 943-958.

Benca, R. M., Obermeyer, W. H., Thisted, R. A. \& Gillin, J. C. (1992). Sleep and psychiatric disorders. Archives of General Psychiatry 49, 651-668.

Benson, K. L. \& Zarcone, V. P. (1985). Testing the REM sleep phasic event intrusion hypothesis of schizophrenia. Psychiatry Research $15,163-173$.

Benson, K. L. \& Zarcone, V. P. (1993). Rapid eye movements in schizophrenia and depression. Archives of General Psychiatry 50 , 474-482.

Borbély, A. A. (1982). A two process model of sleep regulation. Human Neurobiology 1, 195-204.

Buchsbaum, M. S. (1993). Positron-emission tomography and brain activity in psychiatry. In Review of Psychiatry, vol. 12 (ed. J. M. Oldham, M. B. Riba and A. Tasman), pp. 461-485. American Psychiatric Press: Washington, DC.

Caldwell, D. F. \& Domino, E. F. (1967). Electroencephalographic and eye movement patterns during sleep in chronic schizophrenic patients. Electroencephalographic and Clinical Neurophysiology 22, 414-420.

Campbell, S. S. \& Gillin, J. C. (1987). Depressing normal sleep: two tests of the process S deficiency hypothesis. Neuropsychobiology 18. 169-174.

Dürrigl, V., Buranki, I. \& Stofanovic, B. (1973). Characteristics of paradoxical sleep in schizophrenic patients. In Sleep: Physiology, Biochemistry, Psychology, Pharmacology, Clinical Implications (ed. W. P. Koella and R. Levin), pp. 587-591. Karger: Switzerland.

Elul, R. (1972). The genesis of the EEG. In International Review of Neurobiology, vol. 15 (ed. C. C. Pfeiffer and J. R. Smythies), pp. 228-272. Academic Press: New York.

Feinberg, I. (1982). Schizophrenia and late maturational brain changes in man. Psychopharmacology Bulletin 18, 29-31.

Feinberg, I. (1990). Cortical pruning and the development of schizophrenia Schizophrenia Bulletin 16, 567-568.

Feinberg, I., Koresko, R. L. \& Gottlieb, F. (1964). Further observations on electrophysiological sleep patterns in schizophrenia. Comprehensive Psychiatry 5, 44-53.

Feinberg, I., Baker, T., Leder, R. \& March, D. (1988). Response of delta $(0-3 \mathrm{~Hz})$ EEG and eye movement density to a night with 100 minutes of sleep. Sleep 11, 473-487.

Feinberg, I., Thode, H. C., Chugani, H. T. \& March, J. D. (1990). Gamma distribution model describes maturational curves for delta wave amplitude, cortical metabolic rate and synaptic density. Journal of Theoretical Biology 142, 149-161.

Ganguli, R., Reynolds, C. F. \& Kupfer, D. J. (1987). Electroencephalographic sleep in young, never-medicated schizophrenics. Archives of General Psychiatry 44, 36-44.

Gershon, E. S., DeLisi, L. E., Hamovit, J., Nurnberger, J. I., Jr., Maxwell, E., Schreiber, J., Dauphinais, D., Dingman, C. W. \& Guroff, J. J. (1988). A controlled family study of chronic psychoses. Archives of General Psychiatry 45, 328-336.

Gillin, J. C., Sitaram, N., Mendelson, W. B. \& Wyatt, R. J. (1978). Physostigmine alters onset but not duration of REM sleep in man. Psychopharmacology 58, 111-114.

Gillin, J. C., Sutton, L., Ruiz, D., Kelsoe, J., Dupont, R. M., Darko, D., Risch, S. C., Golshan, S. \& Janowsky, D. (1991). The cholinergic Rapid Eye Movement Induction Test with arecoline in depression. Archives of General Psychiatry 48, 264-270.

Gulevich, G. D., Dement, W. C. \& Zarcone, V. P. (1967). All-night sleep recordings of chronic schizophrenics in remission. Comprehensive Psychiatry 8, 141-149.

Hiatt, J. F., Floyd, T. C., Katz, P. H. \& Feinberg, I. (1985). Further evidence of abnormal non-rapid-eye-movement sleep in schizophrenia. Archives of General Psychiatry 42, 797-802.

Hoffman, R. E. \& McGlashan, T. H. (1993). Parallel distributed processing and the emergence of schizophrenic symptoms. Schizophrenia Bulletin 19, 119-140.

Hoffman, R. E., Buchsbaum, M. S., Escobar, M. D. \& Makuch, R. W. (1991). EEG coherence of prefrontal areas in normal and schizophrenic males during perceptual activation. Journal of Neuropsychiatry and Clinical Neurosciences 3, 169-175.

Horne, J. (1992). Human slow wave sleep: A review and appraisal of recent findings, with implications for sleep functions, and psychiatric illness. Experientia 48, 941-954.

Horne, J. A. (1993). Human sleep, sleep loss and behaviour: implications for the prefrontal cortex and psychiatric disorder. British Journal of Psychiatry 162, 413-419.

Huttenlocher, P. R. (1979). Synaptic density in human frontal cortex: developmental changes and effects of aging. Brain Research 163, 195-205.

Jackson, J. H. (1958). Selected Writings of John Hughlings Jackson, vol. 11 (ed. W. Taylor, Jr., G. Holmes, and F. Walshe), p. 412. Basic Books Inc: New York.

Jus, K., Kiljan, A., Wilczak, H., Kubacki, A., Rzepecki, J. \& Jus, A. (1968). Étude polygraphique du sommeil de nuit dans la schizophrénie. Annals of Medicine and Psychology 1, 713-725.

Jus, K., Bouchard, M., Jus, A., Villeneuve, A. \& Lachance, R. (1973). Sleep EEG studies in untreated, long-term schizophrenic patients. Archives of General Psychiatry 29, 386-390.

Kempenaers, C., Kerkhofs, M., Linkowski, P. \& Mendlewicz, J. (1988). Sleep EEG variables in young schizophrenic and depressive patients. Biological Psychiatry 24, 828-833.

Keshavan, M. S., Reynolds, C. F. \& Kupfer, D. J. (1990a). Electroencephalographic sleep in schizophrenia. Comprehensive Psychiatry 30, 34-47.

Keshavan, M. S., Reynolds, C. F., Ganguli, R., Brar, J. S., Houck, P. R. \& Kupfer, D. J. (1990b). EEG sleep in familial subgroups of schizophrenia. (Abstract.) Sleep Research 19, 330.

Keshavan, M. S., Reynolds, C. F., Mahadik, S. P., Mukherjee, S., Korenorsky, A., Jarrett, D. \& Houck, P. (1992). Serum cholinesterase and REM latency in schizophrenia and schizoaffective disorders. Psychiatry Research 43, 23-29.

Kraepelin, E. (1919). Dementia Praecox and Paraphrenia. Livingstone: Edinburgh.

Kupfer, D. J. \& Ehlers, C. L. (1989). Tow roads to rapid eye movement latency. Archives of General Psychiatry 46, 945-948.

Kupfer, D. J., Wyatt, R. J., Scott, J. \& Snyder, F. (1970). Sleep disturbance in acute schizophrenic patients. American Journal of Psychiatry 126, 1213-1223.

Lairy, G., Barte, H., Goldsteinas, L. \& Ridjanovic, S. (1965) Sommeil de nuit des malades mentaux. Le Sommeil de Nuit Normal et Pathologique: Études Électroencéphalographiques 2, 353-381.

Mahadik, S. P., Mukherjee, S., Korenorsky, A., Reddy, R. \& Schnuor, D. B. (1989). Serum cholinesterase isozymes in schizophrenia. Biological Psychiatry 25, 172A. 
Miles, L. E. \& Dement, W. C. (1980). Sleep and aging. Sleep 3, 119-220.

Mukherjee, S., Reddy, R. \& Schnur, D. B. (1991). A developmental model of negative syndromes in schizophrenia. In Negative Schizophrenic Symptoms: Pathophysiology and Clinical Implications (ed. J. F. Greden and R. Tandon), pp. 173-186. American Psychiatric Press: Washington, DC.

Nielsen, T., Godbout, R., Petit, D., Montplaisir, J. \& Abel, A. (1991). Intrahemispheric EEG coherence: role of frontal lobe connections in EEG slow wave generation. (Abstract.) Sleep Research 20, 28.

Pettegrew, J. W., Keshavan, M. S., Panchalingam, K., Strychor, S., Kaplan, D. B., Tretta, M. G. \& Allen, M. (1991). Alterations in brain high-energy phosphate and membrane phospholipid metabolism in first-episode, drug-naive schizophrenics. Archives of General Psychiatry 48, 563-568.

Orzack, M. H., Hartman, E. L. \& Kornetsky, C. (1977). The relationship between attention and slow wave sleep in schizophrenia. Psychopharmacology Bulletin 13, 59-61.

Reynolds, C. F. \& Kupfer, D. J. (1987). Sleep research in affective illness: state of the art circa 1987. Sleep 10, 199-215.

Riemann, D., Fleckenstein, P., Hohagen, F., Olbrich, R. \& Berger, M. (1991). Effects of RS-86 on REM latency in schizophrenia. Psychiatry Research 38, 89-92.

Selemon, L. D., Rajkowska, G. \& Goldman-Rakic, P. S. (1993). A morphometric analysis of the prefrontal areas 9 and 46 in the schizophrenic and normal human brain. (Abstract.) Schizophrenia Research 9, 151.

Sitaram, N., Nurnberger, J., Gershon, E. S. \& Gillin, J. C. (1980). Faster cholinergic REM induction in euthymic patients with primary affective illness. Science 208, 200-202.

Stern, M., Fram, D. H., Wyatt, R., Grinspoon, L. \& Tursky, B.
(1969). All-night sleep studies of acute schizophrenics. Archives of General Psychiatry 20, 470-477.

Tandon, R. \& Greden, J. F. (1989). Cholinergic hyperactivity and negative schizophrenic symptoms: a model of cholinergicdopaminergic interactions in schizophrenia. Archives of General Psychiatry 46, 745-753.

Tandon, R., Greden, J. F., Shipley, J. E., Mann, N. A., Eisner, W. H. \& Goodson, J. (1991). Muscarinic hyperactivity in schizophrenia: relationship to positive/negative symptoms. Schizophrenia Research 4, 23-30.

Tandon, R., Shipley, J. E., Taylor, S., Greden, J. F., Eiser, A DeQuardo, J. \& Goodson, J. (1992). Electroencephalographic sleep abnormalities in schizophrenia. Archives of General Psychiatry 49, 185-194.

Traub, A. C. (1972). Sleep stage deficits in chronic schizophrenia. Psychological Reports 31, 815-820.

van Kammen, D. P., van Kammen, W. B., Peters, J., Goetz, K. \& Neylan, T. (1988). Decreased slow-wave sleep and enlarged lateral ventricles in schizophrenia. Neuropsychopharmacology 1, 265-271.

van Kammen, D. P., Peters, J., Yao, J., van Kammen, W. B., Neylan, T., Shaw, D. \& Linnoila, M. (1990). Norepinephrine in acute exacerbations of chronic schizophrenia. Archives of General Psychiatry 47, 161-168.

Waddington, J. L. (1993). Schizophrenia: developmental neuroscience and pathobiology. Lancel 341, 531-536.

Zarcone, V. P., Benson, K. L. \& Berger, P. A. (1987). Abnormal rapid eye movement latencies in schizophrenia. Archives of General Psychiatry 44, 45-48.

Zipursky, R. B., Lim, K. O., Sullivan, E. V., Brown, B. W. \& Pfefferbaum, A. (1992). Widespread cerebral gray matter volume deficits in schizophrenia. Archives of General Psychiatry 49, 195-205. 